\title{
Tourette syndrome in children
}

Valsamma Eapen, Tim Usherwood

\section{Background}

Gilles de la Tourette syndrome (GTS), characterised by motor and vocal tics, has a prevalence of approximately $1 \%$ in school-aged children. Commonly encountered comorbidities of GTS include attention deficit hyperactivity disorder (ADHD) and obsessivecompulsive behaviour/disorder (OCB/ OCD). Genetic factors play an important part in the aetiology of GTS, and family members may exhibit tics or related disorders such as ADHD, OCB or OCD.

\section{Objective}

The aim of this article is to present a summary of the current evidence to assist the assessment and management of GTS in primary care.

\section{Discussion}

A comprehensive assessment should include exploration of not only tics but also associated features and comorbidities. The stigmatising and impairing nature of tics can have a significant impact on the quality of life of the young person and their parents/ carers, as well as on family functioning. Management includes education and explanation, behavioural treatments and (sometimes) medication.

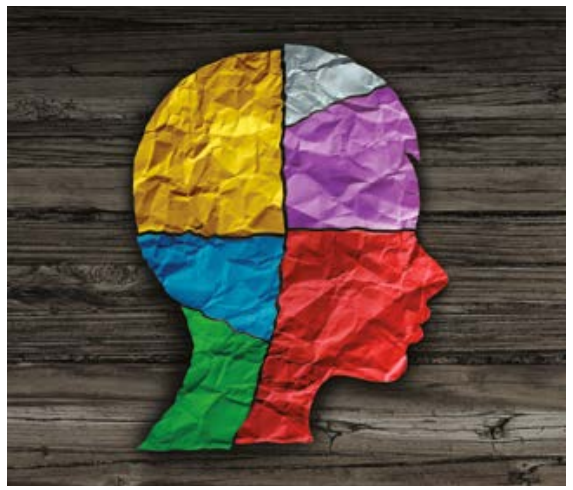

UP TO $20 \%$ OF CHILDREN exhibit rapid jerky movements (motor tics) that are made without conscious intention as part of a developmental phase that often lasts a few weeks to months. ${ }^{1}$ Similarly, involuntary sounds, vocalisations or noises (vocal or phonic tics) such as coughing and even brief screams or shouts may be observed in some children for brief periods of time. Tics lasting for a few weeks to months are known as 'transient tic disorder'. When single or multiple motor or vocal tics - but not a combination of both - have been present for more than one year, the term 'chronic tic disorder' is used. When both (multiple) motor and (one or more) vocal tics have been present for more than a year, with onset before the age of 18 years, the condition is known as Gilles de la Tourette syndrome (GTS) or, in short, Tourette syndrome. ${ }^{2}$

The aim of this article is to review current evidence regarding the assessment and management of GTS.

\section{Prevalence}

Once considered rare, GTS is now understood to be relatively common, occurring in approximately $1 \%$ of school-aged children. ${ }^{3}$ GTS is more common in boys, and the male-to-female ratio is estimated to be $4: 1 .^{4,5}$ Tics have a mean age of onset of 6-7 years, reach peak severity at the age of approximately 10-12 years, and typically improve by adolescence or thereafter. ${ }^{6}$

\section{Clinical features}

In addition to simple motor and vocal/ phonic tics, complex tics may be present (Table 1). Some complex tics - such as spitting, licking, kissing, etc - may be misunderstood or misinterpreted and may result in the young person getting in trouble, especially if these tics include involuntary and inappropriate obscene gesturing (copropraxia) or copying the movements of other people (echopraxia). Similarly, complex vocal tics may include repeating words or phrases or even full sentences (echolalia) or repeating the last word or syllable (palilalia) or, in approximately $10-15 \%$ of cases, involuntary and inappropriate swearing or blurting out of obscenities (coprolalia).

Tics are usually preceded by a premonitory sensation or urge, such as a feeling of tightness, stretch, tension or itching that is relieved by performing the tic, thereby leading to an urge-ticrelief cycle. ${ }^{7,8}$ Patients with GTS may also exhibit a number of associated behaviours such as rage, self-injurious behaviours or non-obscene socially inappropriate behaviours that involve 
socially inappropriate comments or actions. ${ }^{9}$ Attention deficit hyperactivity disorder (ADHD) is encountered in approximately $60-75 \%$ of children with GTS, while obsessive-compulsive disorder (OCD) is reported in $27 \%$, obsessivecompulsive behaviours (OCB) in $32 \%$, and self-injurious behaviours in $25 \% .{ }^{10}$ Although less common, features of autism, learning difficulties, anxiety, depression, phobia, irritability, impulsivity, rage, aggression, sleep difficulties, oppositional or conduct problems, substance use or personality issues may co-exist. ${ }^{11}$ Some individuals' overall academic and social functioning as well as quality of life (QoL) may be affected more by these associated problems than the tics themselves. ${ }^{12}$ Regarding the age of onset, it is noteworthy that symptoms of ADHD may appear between three and six years of age (ie before the tics manifest), while the OCD symptoms usually manifest in late childhood or adolescence.

Tics can come and go, and they take a waxing and waning course. While tics are involuntary, they are sometimes referred to as 'unvoluntary' because the person may be able to suppress the tics for a period of time, and some of the complex tics may be camouflaged to look like purposeful movements. Thus children may voluntarily suppress their tics for short periods of time that may vary from seconds to minutes or hours, but this is at the expense of mounting inner tension and is often followed by a rebound or increase in tics. For example, some children may manage the school hours fairly well without many observable tics but then show increased frequency when they return home. This may lead to a misunderstanding that children can suppress the tics if they try harder. If anxiety and stress worsen the tics, then they may be mistaken as 'psychological' in origin. Rarely, tics may be brought on, or made worse, by a bacterial (eg group A streptococcus) infection such as in paediatric autoimmune neuropsychiatric disorder associated with streptococcal infection.

\section{Aetiology}

Genetics play a major factor in the development of GTS, but the mechanisms are complex. While no single susceptibility gene of large effect has been identified as yet, twin and family studies suggest that it is highly heritable, with a populationbased heritability estimate of $0.771 .^{13}$ Environmental factors are also involved, such as pre- and perinatal factors including difficulties with pregnancy, smoking, exposure to infection, immune or inflammatory factors and psychosocial stressors, as well as birth complications. ${ }^{14}$ Corticostriatal circuitry is implicated in GTS, with excess dopamine levels thought to be the underlying neurochemical abnormality.

\section{Assessment}

Assessment should include a detailed history inquiring about not only tics but also other associated conditions including ADHD, OCD and OCB, in the patient as well as among family members. Tics should be distinguished from involuntary movements due to other conditions (Table 2). ${ }^{5}$ Careful neurological examination may provide reassurance for the patient, parent/carer and doctor.

Once a diagnosis is made, further assessments should include those of comorbid conditions, associated features and the impact of their symptoms (Figure 1).

\section{Social impact and quality of life}

Tics can affect a child's life in a number of ways; these include the impact on school and academic work, social life and relationships as well as physical and mental wellbeing. ${ }^{12}$ The visible nature of the tics may draw attention to the individual or lead to embarrassment, teasing/bullying or social exclusion.

Impact on school work may be due to the effect of tics on learning or due to related conditions such as ADHD, OCD/OCB or an associated learning disorder. ${ }^{15}$ The ability to focus in class and engage in school activities may be reduced as a result of the child spending time and energy on trying to hide or suppress the tics while at school. Other students or teachers may accuse the individual with tics of deliberately 'pulling faces', spitting or disturbing the class through grunts or vocalisations.

QoL has been shown to be lower in people living with GTS when compared with the general population. ${ }^{16}$ Among patients with GTS, individuals without comorbidities have been found to have better QoL than those with comorbidities. ${ }^{17}$ Parent-reported

Table 1. Common tics of Tourette syndrome*

Simple

(involuntary meaningless movements)

Eye blinking, eye rolling, squinting, facial grimaces, shoulder shrugging, arm extending, mouth opening, nose twitching, lip licking, head jerks, brushing or tossing hair out of eyes
Complex

(unvoluntary seemingly purposeful movements)

Pulling of clothes, touching people/objects, poking/jabbing, smelling fingers/objects, punching self, jumping/skipping, kicking, hopping, walking on toes, kissing self or others, feet shuffling, flapping arms, twisting around, twirling hair, selfinjurious behaviour, biting, picking skin or scabs

Vocal/phonic tic Throat clearing, grunting, snorting, yelling/screaming, sniffing, barking, laughing, coughing, spitting, squeaking, humming, whistling, honking
Making small animal-like sounds, unusual changes of pitch and volume of voice, stuttering, repetition of sounds

*This is not an all-inclusive list 
comorbidity in children and adolescents with GTS has been found to be associated with decreased QOL, increased emotional symptomatology and impaired emotional, social (including peer relationship) and school functioning. ${ }^{18}$ Warm and supportive family relationships are integral to long-term social and emotional stability in children with GTS and their QoL. ${ }^{12}$

\section{Management}

Management options for children and young people with GTS include education, explanation and advice; linking with support groups; and behavioural interventions as well as medication. A decision tree on management is outlined in Figure 2. ${ }^{2}$

It is noteworthy that only approximately $10 \%$ of patients with GTS have 'pure Tourette', where they present with only motor and vocal tics. Most patients with
GTS have 'Tourette-plus', where one or more comorbid conditions are present (Figure 3). ${ }^{9}$ Management in these situations should take into account the symptoms that are causing most distress or dysfunction.

\section{Education, explanation and advice}

All affected children and their families need information about the nature and course of GTS and any accompanying conditions, and advice on how to manage tics. For mild cases, advice regarding tic management may be all that is needed. It is important to emphasise to the parents/carers and child that the tics are involuntary and outside the child's control, and that they cannot help these sudden movements or voices/noises. A parallel may be drawn with trying to supress a sneeze or avoid blinking.

The young person and their family may be linked up with the Tourette Syndrome
Association of Australia, and the health professional that they have consulted may provide information to schools or other environments in which the child interacts. The biological nature of tics should be highlighted, and it should be emphasised that they are not due to stress or 'bad parenting'.

Following assessment and explanation about the nature of the condition, moderate cases may benefit from referral to a psychologist for behavioural methods of treatment. When the tics are severe with associated distress and/or dysfunction, or when significant comorbidities are present, the general practitioner (GP) may refer the patient to a specialist with expertise in GTS for a comprehensive assessment and management plan. GPs can refer to clinical psychologists under a mental healthcare plan for the implementation of behavioural treatments.

\section{Table 2. Differential diagnosis of Tourette syndrome ${ }^{5}$}

\begin{tabular}{ll}
\hline Diagnosis & Characteristic feature \\
\hline Gilles de la Tourette syndrome & $\begin{array}{l}\text { Onset at approximately 6-7 years of age, with further emergence of symptoms that peak at } \\
\text { approximately 10-12 years of age, and remission post-adolescence; waxing and waning course; } \\
\text { the type and site of tics changes from one place to another; voluntarily suppressible for short } \\
\text { periods of time }\end{array}$
\end{tabular}

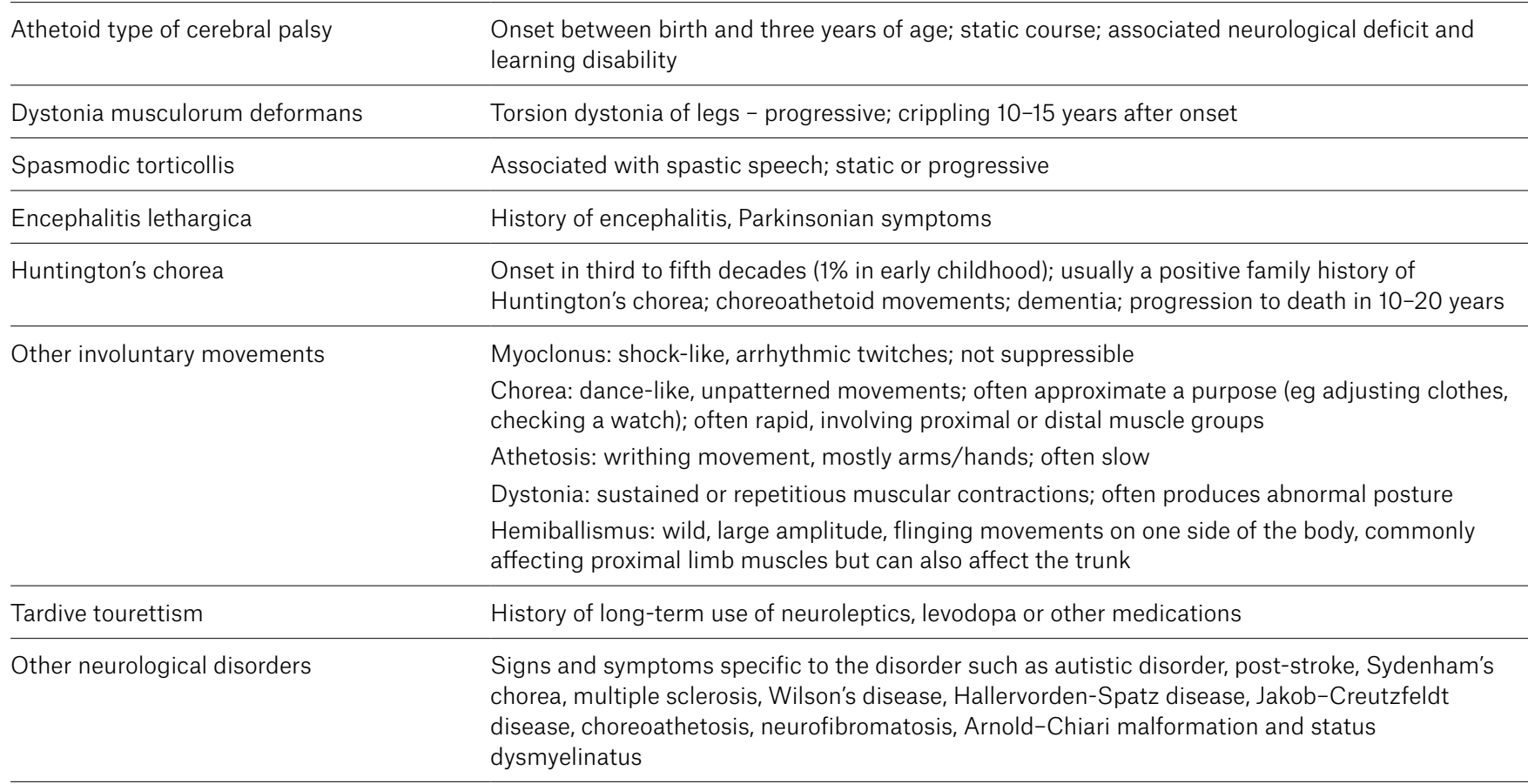




\section{Behavioural methods of treatment} For children with mild-to-moderate tics, effective treatments include specific behavioural techniques such as exposure and response prevention (ERP), habit reversal therapy (HRT) ${ }^{19}$ and comprehensive behavioural intervention for tics (CBIT).$^{20}$ In ERP, the patient is trained to stay exposed, endure the premonitory urge and prevent or resist performing the tic symptoms. In HRT, patients are trained to do competing responses instead of performing the tics, and the program consists of awareness training with self-monitoring, relaxation training and competing response training. CBIT combines awareness training with competing response training and social support. Following awareness training, patients are taught to engage in a 'competing response' every time the urge or tic occurs. The social support component involves teaching the patient's parent (or another person) to praise the patient for using the competing response correctly and to remind the patient to use the competing response.

\section{Medication}

For moderate-to-severe tics and other features of GTS causing either distress or dysfunction, it is worthwhile considering medication. The following medications may be useful.

Centrally acting $\alpha$-adrenergic agents such as clonidine or guanfacine are usually the first line of treatment, especially if tics and hyperactivity are both present. It is important to monitor blood pressure as these agents can cause hypotension. There is also a risk of rebound hypertension if the medication is ceased abruptly.

\section{Patient presents with tics.} suspected if:

- multiple motor and at least one vocal or phonic tic are present

- tics have been present for $>1$ year

- tics started before the age of 18 years.

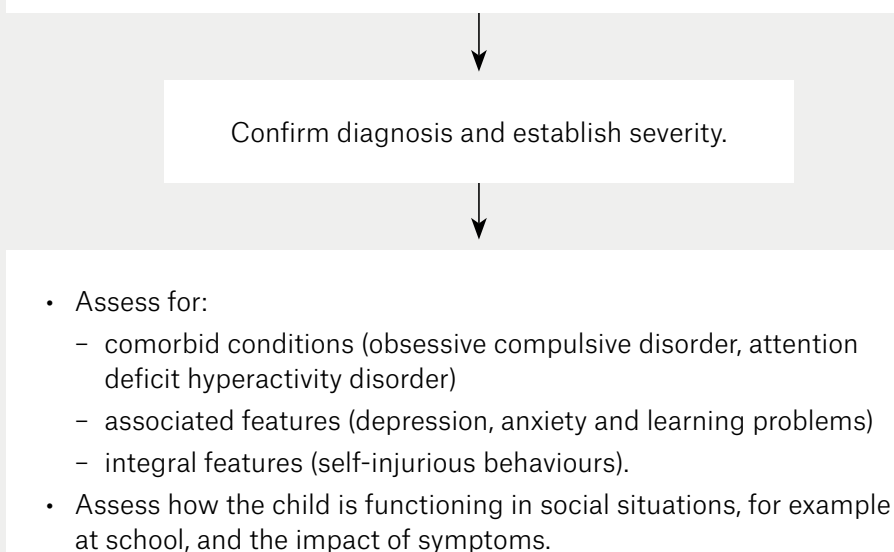
at school, and the impact of symptoms.

Figure 1. Assessment of patients presenting with tics

Small doses of antipsychotics, such as risperidone, aripiprazole, amisulpride or haloperidol, can help control the tics. It is recommended that patients are prescribed a low dose, which is then increased slowly if side effects do not occur. First-generation antipsychotics such as haloperidol have been the treatment of choice since the 1960s but are used less frequently nowadays because of the risk of extrapyramidal syndromes. Weight gain and metabolic effects need to be monitored when a patient is prescribed second-generation antipsychotics such as risperidone or aripiprazole. When considering the choice of medication for tics, the effects of the medication on comorbid disorders also deserve consideration. For example, clonidine can be useful when the patient also has ADHD and sleep problems, while risperidone can have additional benefits when comorbid aggression and behavioural problems are present. Aripiprazole has been found to augment the therapeutic response to selective serotonin reuptake inhibitors in patients who also have OCD, anxiety or major depressive disorder. ${ }^{21}$

Less commonly used treatments that are typically reserved for complex cases with comorbid epilepsy and other complexities include anticonvulsants (eg topiramate, carbamazepine, levetiracetam), benzodiazepines (eg clonazepam) and cannabinoids. ${ }^{2}$

Although not used in children, in adults with severe refractory and treatmentresistant GTS, deep-brain stimulation (DBS) has been used with some success. ${ }^{22}$ DBS involves the implantation of electrodes for chronic stimulation aimed at modulating neuronal activity in target regions. There is significant heterogeneity in outcomes, and there is also a lack of consensus regarding the ideal brain target; therefore, further research is needed.

\section{Conclusion}

Tics are frequently under-recognised or misdiagnosed; simple tics may be discounted as habits, and complex tics as behavioural disorders. Increased awareness of the condition and better supports are sorely needed. 
Tic disorder

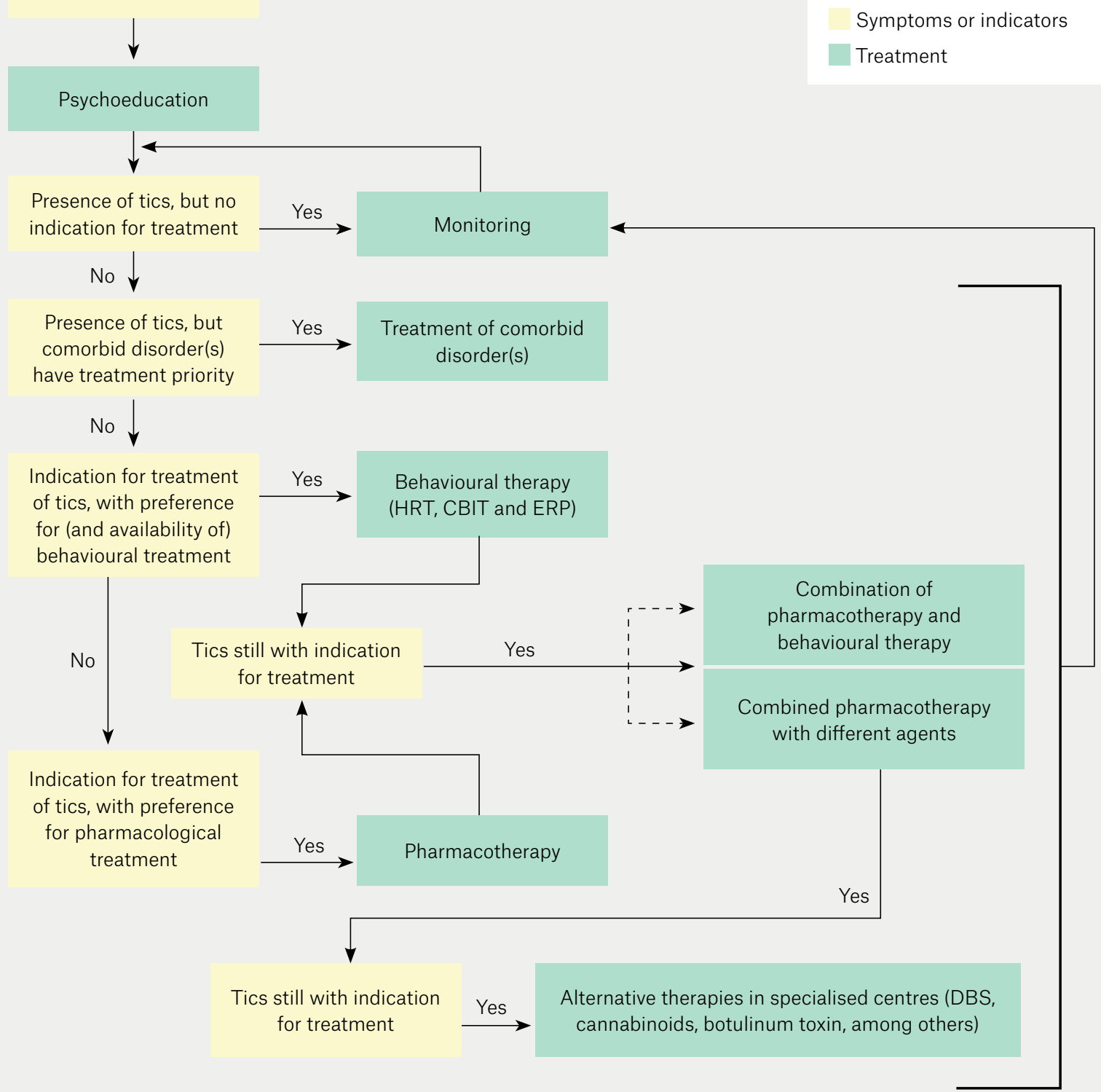

Figure 2. Decision tree for the management of Tourette syndrome

$C B I T$, comprehensive behavioural intervention for tics; DBS, deep-brain stimulation; ERP, exposure and response prevention; HRT, habit reversal therapy Reproduced with permission from Robertson MM, Eapen V, Singer HS, et al, Gilles de la Tourette syndrome, Nat Rev Dis Primers 2017;3:16097, doi: 10.1038/nrdp.2016.97.

\section{Key points}

- Motor tics occur in up to $20 \%$ of children as a developmental phase but usually do not last longer than a year.

- GTS is diagnosed when there are several motor tics and at least one vocal tic that have been present for more than a year.
- GTS occurs in around $1 \%$ of school-aged children.

- Tics usually appear around the age of 6-7 years, increasing in severity until the age of approximately 10-12 years, after which they start to reduce and in the majority of cases - become considerably better by young adulthood.

- For mild cases, explanation and advice about the condition may be sufficient, while moderate-to-severe cases will benefit from referral to a specialist with expertise in the assessment and management of GTS. 


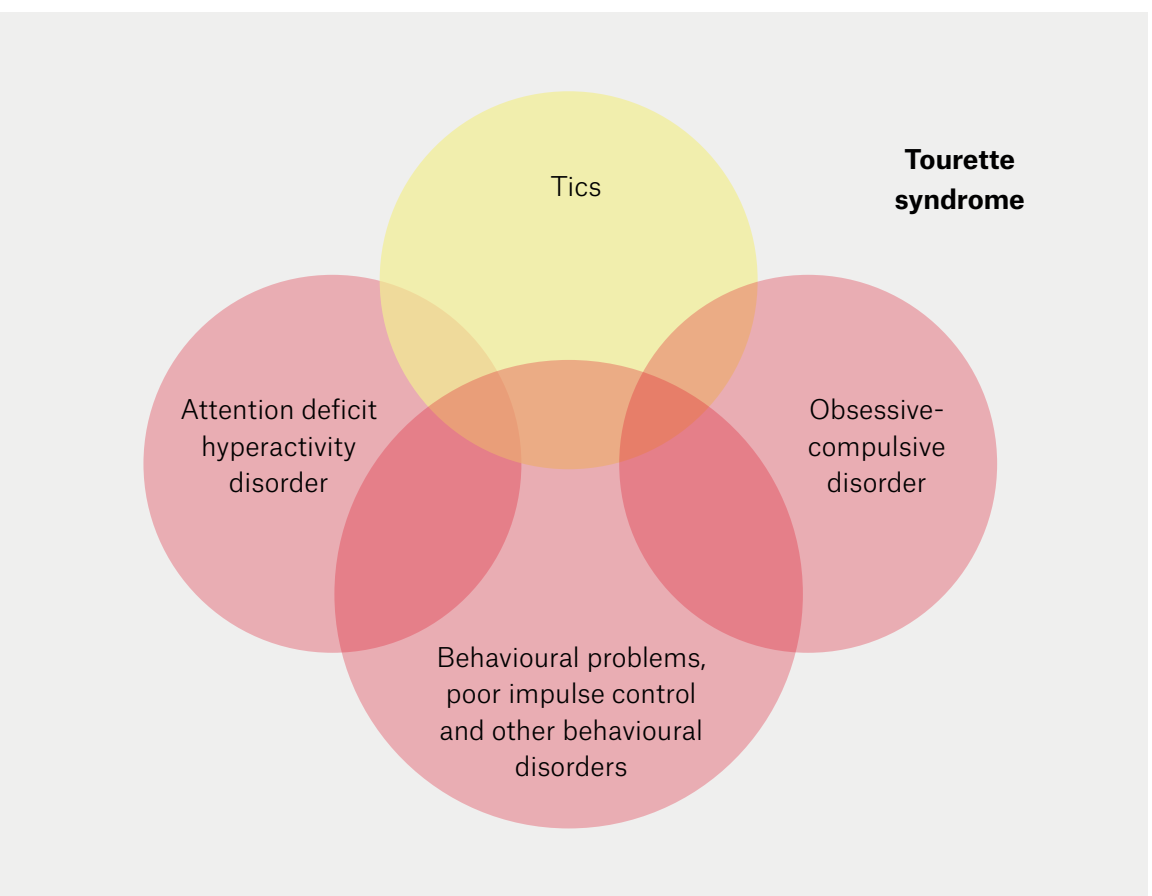

Figure 3. Conditions associated with Tourette syndrome

- No single cause has been found for GTS, but the major contributing factors include genetics and pre- and perinatal difficulties.

- Ninety per cent of people living with GTS will experience comorbid conditions such as ADHD or OCD/ $\mathrm{OCB}$ or associated features such as depression and anxiety.

\section{Authors}

Valsamma Eapen MBBS, PhD, FRCPsych, FRANZCP, Chair, Infant Child and Adolescent Psychiatry, University of New South Wales, NSW; Head, Academic Unit of Child Psychiatry, South West Sydney (AUCS), NSW; Stream Director, Early Life Determinants of Health, Sydney Partnership for Health, Education, Research and Enterprise (SPHERE), NSW; Director, Program 1, Co-operative Research Centre for Autism (CRC), Qld; Director BestSTART-SW (Systems Transformation and Research Translation - South West Sydney) Academic Unit, NSW

Tim Usherwood BSc, MBBS, MD (Res), DMS, FRCP, FRCGP, FRACGP, FAICD, Head, Westmead Clinical School, The University Of Sydney, NSW; Professor of General Practice, Faculty of Medicine and Health, The University of Sydney, NSW; Honorary Professorial Fellow, The George Institute for Global Health، Sydney, NSW

Competing interests: TU has lived with Tourette syndrome since the age of six years.

Funding: None.

Provenance and peer review: Commissioned, externally peer reviewed.

\section{Correspondence to:}

v.eapen@unsw.edu.au

\section{References}

1. Black KJ, Black ER, Greene DJ, Schlaggar BL. Provisional tic disorder: What to tell parents when their child first starts ticcing. F1000Res 2016;5:696. doi: 10.12688/f1000research.8428.1.

2. Robertson MM, Eapen V, Singer HS, et al. Gilles de la Tourette syndrome. Nat Rev Dis Primers 2017;3:16097. doi: 10.1038/nrdp.2016.97.

3. Robertson MM. A personal 35 year perspective on Gilles de la Tourette syndrome: Prevalence, phenomenology, comorbidities, and coexistent psychopathologies. Lancet Psychiatry 2015;2(1):68-87. doi: 10.1016/S22150366(14)00132-1.

4. Jankovic J, Kurlan R. Tourette syndrome: Evolving concepts. Mov Disord 2011;26(6):1149-56. doi: $10.1002 /$ mds. 23618

5. Kurlan R. The differential diagnosis of tic disorders. In: Martino D, Leckman JF, editors. Tourette syndrome. New York, NY: Oxford University Press, 2013; p. 395-401.

6. Bloch MH, Peterson BS, Scahill L, et al. Adulthood outcome of tic and obsessivecompulsive symptom severity in children with Tourette syndrome. Arch Pediatr Adolesc Med 2006;160(1):65-69. doi: 10.1001/archpedi.160.1.65.

7. Leckman JF, Walker DE, Cohen DJ. Premonitory urges in Tourette's syndrome. Am J Psychiatry 1993;150(1):98-102. doi: 10.1176/ajp.150.1.98.

8. Woods DW, Piacentini J, Himle MB, Chang S Premonitory urge for tics scale (PUTS): Initial psychometric results and examination of the premonitory urge phenomenon in youth with tic disorders. J Dev Behav Pediatr 2005;26(6):397-403. doi: 10.1097/00004703200512000-00001.
9. Eapen V, Robertson MM. Are there distinct subtypes in Tourette syndrome? Pure-Tourette syndrome versus Tourette syndrome-plus, and simple versus complex tics. Neuropsychiatr Dis Treat 2015;11:1431-36. doi: 10.2147/NDT.S72284

10. Freeman RD, Fast DK, Burd L, Kerbeshian J, Robertson MM, Sandor P. An international perspective on Tourette syndrome: Selected findings from 3,500 individuals in 22 countries. Dev Med Child Neurol 2000:42(7):436-47. doi: 10.1017/s0012162200000839.

11. Eapen V Črnčec R, McPherson S, Snedden C. Tic disorders and learning disability: Clinical characteristics, cognitive performance and comorbidity. Australas J Spec Educ 2013;37(2):162-72. doi: 10.1017/jse.2013.2.

12. Eapen V, Cavanna AE, Robertson MM Comorbidities, social impact, and quality of life in Tourette syndrome. Front Psychiatry 2016;7:97. doi: 10.3389/fpsyt.2016.00097.

13. Mataix-Cols D, Isomura $K$, Pérez-Vigil $A$, et al. Familial risks of Tourette syndrome and chronic tic disorders. A population-based cohort study. JAMA Psychiatry 2015;72(8):787-93. doi: 10.1001/ jamapsychiatry.2015.0627.

14. Eapen V, Perkes I, Goff R. Pathways from genes to symptoms in Gilles de la Tourette syndrome (GTS). In: Martino D, Leckman JF, editors. Tourette syndrome. New York, NY: Oxford University Press, 2021 [in press].

15. Dornbush MP, Pruitt SK. Teaching the tiger: A handbook for individuals involved in the education of students with attention deficit disorders, Tourette syndrome, or obsessive-compulsive disorder. Carol Stream, IL: Hope Press, 1995.

16. Elstner K, Selai CE, Trimble MR, Robertson MM Quality of life (QOL) of patients with Gilles de la Tourette's syndrome. Acta Psychiatr Scand 2001;103(1):52-59. doi: 10.1034/j.16000447.2001.00147.x.

17. Eapen V, Snedden C, Črnčec R, Pick A, Sachdev P. Tourette syndrome, co-morbidities and quality of life. Aust N Z J Psychiatry 2016;50(1):82-93. doi: 10.1177/0004867415594429.

18. O'Hare D, Helmes E, Reece J, Eapen V, McBain K. The differential impact of Tourette's syndrome and comorbid diagnosis on the quality of life and functioning of diagnosed children and adolescents. J Child Adolesc Psychiatr Nurs 2016;29(1):30-36. doi: 10.1111/jcap.12132.

19. Capriotti MR, Himle MB, Woods DW. Behavioral treatments for Tourette syndrome. J Obsessive Compuls Relat Disord 2014;3(4):415-20. doi: 10.1016/j.jocrd.2014.03.007.

20. Piacentini J, Woods DW, Scahill L, et al. Behavior therapy for children with Tourette disorder: A randomized controlled trial. JAMA 2010;303(19):1929-37. doi: 10.1001/jama.2010.607.

21. Eddy CM, Rickards HE, Cavanna AE. Treatment strategies for tics in Tourette syndrome. Ther Adv Neurolo Disord 2011;4(1):25-45. doi: 10.1177/1756285610390261.

22. Martinez-Ramirez D, Jimenez-Shahed J, Leckman JF, et al. Efficacy and safety of deep brain stimulation in Tourette syndrome: The International Tourette Syndrome Deep Brain Stimulation Public Database and Registry. JAMA Neurol 2018;75(3):353-59. doi: 10.1001/ jamaneurol.2017.4317.

correspondence ajgp@racgp.org.au 